\title{
General practice and ethnicity: an experimental study of doctoring
}

\author{
Brice Lepièce*, Christine Reynaert, Philippe van Meerbeeck and Vincent Lorant
}

\begin{abstract}
Background: There is extensive evidence of health inequality across ethnic groups. Inequity is a complex social phenomenon involving several underlying factors, including ethnic discrimination. In the field of health care, it has been established that ethnic discrimination stems partially from bias or prejudice on the part of doctors. Indeed, it has been hypothesized that patient ethnicity may affect doctors' social cognition, thus modifying their social interactions and decision-making processes. General practitioners (GPs) are the primary access point to health care for ethnic minority groups. In this study, we examine whether patient ethnicity affects the relational and decisional features of doctoring.
\end{abstract}

Methods: The sample was made up of 171 Belgian GPs, who were each randomly allocated to one of two experimental conditions. One group were given a hypertension vignette case with a Belgian patient (non-minority patient), while the other group were given a hypertension vignette case with a Moroccan patient (minority patient). We evaluated the time devoted by GPs to examining medical history; time devoted by GPs to examining socio-relational history; cardiovascular risk assessments by GPs; electrocardiogram (ECG) recommendations by GPs, and drug prescriptions by GPs.

Results: We observed that for ethnic minority patients, GPs prescribed more drugs and devoted less time to examining socio-relational history. Neither cardiovascular risk assessments nor ECG recommendations were affected by patient ethnicity. GPs who were very busy devoted less time to examining medical history when dealing with minority patients.

Conclusions: We found no evidence that GPs discriminated against ethnic minority patients when it came to medical decisions. However, our study did identify a risk of drugs being used inappropriately in some ethnic-specific encounters. We also observed that, with ethnic minority patients, GPs engage less in the relational dimension of doctoring, particularly when working within a demanding environment. In general practice, the quality of the relationship between doctor and patient is an essential component of the effective management of chronic illness. Our research highlights the complexity of ethnic discrimination in general practice, and the need for further studies.

Keywords: Health inequality, General practice, Medical decisions, Doctor-patient relationship, Ethnic discrimination

\section{Background}

Inequalities in health status for ethnic minority groups are well documented, with ethnic minorities consistently faring worse in terms of morbidity and mortality [1-3]. Moreover, in recent years, the gap in mortality rates has widened critically for many illnesses [4].

\footnotetext{
* Correspondence: brice.lepiece@uclouvain.be

Institute of Health and Society, Université Catholique de Louvain, Clos

Chapelle-aux-Champs 30, box 3016-1200, Brussels, Belgium
}

Many factors have been suggested to explain these health inequalities. Shavers listed the factors most commonly assessed in research: access to health care; socioeconomic status; lack of knowledge of the health care system; cultural beliefs or preferences, and race/ethnicity-based discrimination [5].

Smedley concluded that ethnic discrimination existed at all levels of health care, from the policy level to the level of the individual provider [6]. Smedley's research showed that for a wide range of medical procedures, ranging from 
highly technological interventions to basic diagnostic and treatment procedures, minority patients are less likely to receive adequate medical procedures and more likely to experience a poorer quality of medical care than nonminority patients. This pattern of differences remained true even when studies adjusted for differences in patients' health insurance, socio-economic status, the stage and severity of the disease, and comorbidity.

Pager suggested three major mechanisms as underlying contemporary forms of ethnic discrimination: the individual level, the organizational level, and the structural level [7]. In this paper, we focus on the individual level of ethnic discrimination in health care. According to van Ryn, negative stereotypes that doctors have about ethnic minorities are likely to play a role in discrimination during medical encounters [8]. Explicit and implicit biases on behalf of providers can lead to discrimination in health care for ethnic minorities and, ultimately, to disparities in health [9-12]. These stereotypes negatively influence the course and the outcomes of clinical encounters and lead to distrust within inter-ethnic medical interactions $[11,13]$.

Tajfel described "in-group bias", and showed, through a set of pioneering experiments, that humans tend to favor in-group members over out-group members in the distribution of rewards, even when these groups are arbitrarily categorized [14]. The idea is that we like, and are more motivated to help, people that we think are like us [9]. Even though doctors are bound by professional and ethical standards to help and care for vulnerable patients, they may unknowingly stereotype members of ethnic minorities, particularly when working under conditions that diminish cognitive capacity, such as time pressure, fatigue, and information overload [15].

There is extensive evidence to indicate that patient ethnicity modifies conscious and unconscious beliefs and practices on the part of doctors [16-19]. Doctors may be unaware of the fact that they hold implicit attitudes and stereotypes about ethnicity, but these implicit social biases can significantly influence quality of care [19]. According to van Ryn, these biases affect doctors when it comes to decisionmaking, interactions, and inter-personal behaviors [8]. For example, there is evidence that doctors contribute to ethnicity inequities in access to kidney transplants, cardiac procedures, psychiatric care, and pain control [8]. Ethnic minority patients are also more likely than non-minority patients to be recommended for unnecessary surgery [20]. Another major dimension of doctoring that is affected in inter-ethnic consultations is communication and the doctor-patient relationship [21]. For example, Roter revealed that when dealing with black patients, American physicians were more likely to adopt a "narrowly biomedical" communication pattern, characterized by low levels of patient control over communication, low levels of psychosocial talk, and high levels of biomedical information-giving
[22]. Johnson found that doctors were less patient-centered, more verbally dominant, and expressed less positive affect with African-American patients compared to white patients [23]. Kaplan and Cooper found that minority patients rated their physician as having a less participatory decisionmaking style than did non-minority patients [24,25].

There has been little research focusing on ethnic discrimination in general practice. Indeed, most studies on this topic have been conducted within the field of Specialized Medicine. However, GPs are often the primary access to health care for ethnic minority groups, and play a 'gatekeeper' role within the health care system [26]. An investigation into the issue of ethnic discrimination with respect to general practitioners is therefore relevant [27]. Moreover, most of the research and most of the publications on ethnic discrimination in health care have come from the U.S.A., a societal context that is characterized by a long history of migration and racial segregation. Our study was conducted in Belgium, which provides a different societal, historical, and cultural context, as well as a different organization of the health care system. It has been shown that different contexts may lead to different medical practices in terms of ethnic discrimination. For example, one study concluded that the Danish health care system was equitable for ethnic minority groups [28]. In 2011, the resident foreign population represented $10.2 \%$ of the entire population of Belgium [29,30]. The principal ethnic minority groups living in Belgium are Moroccans, Turks, and Congolese [30].

The main aim of this study was to investigate ethnic discrimination in general practice. Our general research hypothesis was that GPs would be more favorable towards non-ethnic minority patients (in-group members) and less favorable towards ethnic minority patients (outgroup members). We used the van Ryn model to analyze the effect of patient ethnicity on GPs. This model suggests that there are two major pathways that lead doctors to give different treatment during medical consultations. The first pathway is the cognitive or decisional dimension, the second one is the interpersonal dimension [8]. In this paper, we assess whether patient ethnicity implies systematic differences in the medical care patients receive. In order to test our research hypothesis, we considered the outcome relative to GPs' decision-making (assessment, recommendation, and prescription) and the outcome relative to the relational aspect of care (time devoted by GPs to examining patients' medical case history), as suggested by van Ryn. Although the relational dimension of doctoring can be evaluated using many factors, in this study we will measure only one of these: time devoted to patient. It has been argued that consultation duration can be considered to be a generic enabling resource and a reliable indicator of the quality of the relationship and quality of care in general [31-37]. We also looked at whether GPs' working 
conditions led to differential medical care for ethnic minority patients.

\section{Methods \\ Study design}

Belgian GPs were randomly assigned one of two case vignettes in which every factor except patient ethnicity was identical. The vignette consisted of a written medical description of a hypothetical patient and was provided to GPs within the questionnaire. Patient ethnicity was altered by modifying the name of the patient in the vignette to create two experimental conditions. The non-minority patient condition featured a Belgian patient named Jean-Pierre, while the ethnic minority patient condition featured a Moroccan patient named Mohamed. One group of GPs was therefore given a non-minority patient, while the other was given an ethnic minority patient. The patient in both vignettes presented with the same hypertensive disease and the same environmental information. Patient ethnicity was therefore our main manipulated independent variable.

\section{Medical vignette}

Hypertension is a highly prevalent disease with potentially serious impacts on morbidity and mortality within populations. GPs play a central role in the management of this disease in terms of early detection, treatment, control, and referrals [38,39].

The medical vignette consisted of a high blood pressure disorder (hypertension) with associated risk factors: tobacco use, being overweight and physical inactivity. GPs were also given some medical information: current blood pressure $(185 / 90 \mathrm{mmHg})$, cardiac frequency $(84 \mathrm{bpm})$, BMI, and results from a blood analysis conducted 15 days previously. The patient's age was also given, as well as some environmental information about the patient's family composition (i.e. number of children, marital status), and professional situation (Additional file 1).

\section{Participants}

A sample of 171 general practitioners (GPs) participated in the study $(\mathrm{n}=171)$. The average age of the total sample was 47.03 years old $(S D=13.76)$. The gender composition of the sample was 86 males $(50.3 \%)$ and 85 females (49. 7\%).

Since we used a fictitious patient with fictitious medical data (in the medical vignette), we judged it unnecessary to request approval from any ethics committee. The study instructions stated that participation in the study was free and on a voluntary basis. All of the participants were adults (Family Practitioners). Participants were therefore not required to complete any consent statement.

\section{Data collection}

Data was collected in three different cities (Charleroi, Liège, and Namur) in the Francophone part of Belgium, on three separate occasions between January and March 2012. At each site, all of the GPs were attending an accredited conference day organized by the Belgian Scientific Society of General Medicine. Questionnaires were randomly distributed to GPs as they arrived to register at the conference. The GPs filled in the questionnaires by hand and returned them to the researcher by the end of the day. The GPs were not aware of the study hypotheses, because the survey was presented as research into the "quality of medical decisions". To encourage GPs to participate in the study, a lottery ticket was given to those who completed the questionnaire. The average participation rate for the study was $45 \%$.

\section{Outcomes measures}

The medical activities of GPs can be classified according to two dimensions: relational and medical decisions. The relational dimension of doctoring includes two variables: time devoted to examining medical history and time devoted to examining socio-relational history. Medical decisions include three variables: cardiovascular risk assessment (from 0 to 10 , where $0=$ no risk and $10=$ maximum risk); the medical utility of recommending an electrocardiogram (ECG) (from 0 to 10 , where $0=$ no utility and $10=$ maximum utility), and whether any antihypertensive drug was prescribed (yes/no).

\section{Statistical analysis}

We considered the following characteristics of the GPs: sex, age, ethnicity, type of practice, patient contact per week, hours worked per week, and practice location. Independent samples T-tests were used to assess the effect of the condition (patient ethnicity) on continuous outcomes (time devoted to medical history examination, time devoted to socio-relational history examination, cardiovascular risk assessment, and ECG recommendation). A chi-squared $\left(x^{2}\right)$ analysis was used to assess the effect of the condition on the categorical outcome (drug prescription). We also considered that some characteristics of GPs, such as sex, type of practice (solo vs. group), practice location (rural vs. urban), and volume of activity, could moderate the effect of patient ethnicity on the GPs' medical activities. It has been shown that restrictive working environments diminish the cognitive capacity of GPs and thus increase the likelihood of discrimination [15]. General linear models (GLM) were used to assess interactions between patient ethnicity and GP characteristics for medical activities. All statistical analyses were carried out using IBM SPSS 20.0 for Windows. 


\section{Results}

\section{GP characteristics}

Table 1 shows the main characteristics of GPs in our sample, arranged by experimental condition. We found no significant differences in the distribution of GP characteristics between the two experimental conditions. Compared to what is average for the general population of GPs in Belgium, we had more GPs in our sample that were female ( $49.7 \%$ vs. $33 \%$ ), young ( 47.03 vs. 50.25 ), working in group practices (57. $3 \%$ vs. $75 \%$ ) and had slightly lower caseloads.

\section{Case vignette comparison by patient ethnicity}

Through random distribution, 84 GPs (49. 1\% of the total sample) were assigned the non-minority patient vignette and 87 GPs (50. 9\% of the total sample) were assigned the ethnic minority patient vignette. We compared

Table 1 Characteristics of Belgian GPs sample by experimental condition ( $N=171), 2012$

\begin{tabular}{|c|c|c|c|c|}
\hline GPs exposed to & $\begin{array}{c}\text { Non-minority } \\
\text { patient }\end{array}$ & $\begin{array}{c}\text { Minority } \\
\text { patient }\end{array}$ & $\mathrm{N}$ total & $\%$ \\
\hline Male & 39 & 47 & 86 & 50.3 \\
\hline Female & 45 & 40 & 85 & 49.7 \\
\hline \multicolumn{5}{|l|}{ Age (yr) } \\
\hline $26-30$ & 16 & 15 & 31 & 18.2 \\
\hline $31-40$ & 14 & 16 & 30 & 17.6 \\
\hline $41-50$ & 13 & 11 & 24 & 14.1 \\
\hline $51-60$ & 26 & 28 & 54 & 31.8 \\
\hline$>61$ & 15 & 16 & 31 & 18.2 \\
\hline \multicolumn{5}{|l|}{ Ethnicity } \\
\hline White & 79 & 85 & 164 & 95.9 \\
\hline \multicolumn{5}{|l|}{ Type of activity } \\
\hline Solo & 47 & 51 & 98 & 57.6 \\
\hline Group & 36 & 36 & 72 & 42.4 \\
\hline \multicolumn{5}{|l|}{$\begin{array}{l}\text { Patient contacts } \\
\text { per week }\end{array}$} \\
\hline$<60$ & 17 & 17 & 34 & 21.5 \\
\hline $60-120$ & 49 & 48 & 97 & 61.4 \\
\hline$>121$ & 13 & 14 & 27 & 17.1 \\
\hline \multicolumn{5}{|l|}{$\begin{array}{l}\text { Medical activity } \\
\text { hours per week }\end{array}$} \\
\hline $8-40$ & 22 & 19 & 41 & 24.9 \\
\hline $41-60$ & 52 & 48 & 100 & 60.6 \\
\hline$>61$ & 10 & 14 & 24 & 14.5 \\
\hline \multicolumn{5}{|l|}{$\begin{array}{l}\text { Activity } \\
\text { localization }\end{array}$} \\
\hline Rural & 32 & 35 & 67 & 40.4 \\
\hline Semi-Urban & 29 & 24 & 53 & 31.9 \\
\hline Urban & 20 & 26 & 46 & 27.7 \\
\hline
\end{tabular}

the medical activities of GPs according to the experimental conditions (patient ethnicity). Our results revealed no significant difference between the two conditions for the following outcomes: time devoted to examining medical history, cardiovascular risk assessment, and ECG recommendation. However, we found that for ethnic minority patients, GPs devoted less time to examining socio-relational history than for non-minority patients $(\mathrm{t}=4.05, \mathrm{p}=0.001)$. Furthermore, our data suggests that ethnic minority patients are more likely to be prescribed an antihypertensive than non-minority patients $\left(\chi^{2}=5.51, \mathrm{p}=0.01\right)$ (Table 2).

We found that the number of patient contacts per week interacted significantly with patient ethnicity in terms of time devoted to examining medical history $(\mathrm{F}=5.71, \mathrm{p}<$ $0.05)$. GPs with high volumes of activity were more discriminatory than GPs with lower volumes of activity: the former devoted less time to examining medical history when dealing with an ethnic minority patient than when dealing with a non-minority patient (Figure 1 ).

We found no other significant interactions between characteristics of GPs and patient ethnicity for medical activities.

\section{Discussion}

This is one of the first experimental studies to investigate ethnic discrimination in general practice. Since GPs are 'gatekeepers' to the health care system, this issue is particularly relevant. Based on van Ryn's model, we hypothesized that patient ethnicity would affect the quality of medical care through (a) biased medical decisions by GPs and (b) biased relational involvement on the part of GPs.

Before beginning a decision-making process, GPs evaluate a patient's cardiovascular risk. We observed that cardiovascular risk assessment was not related to patient ethnicity. The next step is the medical decision and recommendation. Again, ethnicity was not related to ECG procedure recommendation. However, we detected that drug prescription was significantly more frequent for ethnic minority patients than for nonminority patients. These results are inconsistent with our first hypothesis, since ethnicity did not lead to an obvious decrease in the quality of medical decisions or recommendations. On the contrary, ethnic minority patients received more pharmacological treatment than non-minority patients. This result is surprising because previous studies have usually described fewer drug prescriptions for ethnic minority patients suffering from cardiovascular diseases than for non-minority patients [40]. So why did GPs in our study prescribe more drugs for ethnic minority patients, when the cardiovascular risk was equivalent in both groups? One possible explanation is that GPs may consider ethnic minority patients to belong to an at-risk population, due to their ethnicity, and therefore prescribe medication as a 
Table 2 Differences in medical activities of GPs by experimental exposition to patient's ethnicity, Belgium, 2012

\begin{tabular}{|c|c|c|c|c|c|c|c|c|}
\hline \multirow[t]{2}{*}{ Medical activities: Relation \& Decisions } & \multicolumn{3}{|c|}{ Ethnic minority patient } & \multicolumn{3}{|c|}{ Non ethnic minority patient } & \multirow[b]{2}{*}{$t / x^{2}$} & \multirow[b]{2}{*}{ p-value } \\
\hline & $\mathrm{N}$ & Mean/\% & SD ( $\sigma)$ & $\mathrm{N}$ & Mean/\% & SD ( $(\sigma)$ & & \\
\hline \multicolumn{9}{|l|}{ Relation } \\
\hline 1. Medical history examination (time in minutes) & 85 & 4,05 & 3,53 & 84 & 4,43 & 2,35 & $-1,06$ & 0,29 \\
\hline 2. Socio-relational history examination (time in minutes) & 87 & 2,11 & 1,43 & 84 & 3,36 & 2,48 & 4,05 & 0,001 \\
\hline \multicolumn{9}{|l|}{ Decisions } \\
\hline 3. Cardiovascular risk assessment (score from 0 "no risk" to 10 "max risk") & 85 & 6,32 & 1,70 & 82 & 6,34 & 1,56 & 0,05 & 0,96 \\
\hline 4. ECG recommendation (score from 0 "no utility" to 10 "max utility") & 85 & 5,42 & 3,04 & 83 & 5,13 & 2,91 & $-0,06$ & 0,53 \\
\hline 5. Drug prescription (Yes/No) & 85 & $70 \%$ & - & 83 & $53 \%$ & - & 5,51 & 0,01 \\
\hline
\end{tabular}

protective measure. GPs may have considered that most cardiovascular risk factors are more prevalent in ethnic minority populations than in the rest of the population [41]. For example, in Belgium, ethnic minorities are more likely to be living in a poorer socio-economic environment than the general population $[42,43]$. The general health status of ethnic minorities in Belgium is worse than that of the general population [44]. Ethnic minorities are more exposed to cardiovascular risk factors and therefore incur higher cardiovascular morbidity and mortality $[45,46]$. Research indicates that doctors over-apply population statistics to individual patients [47]. Population statistics may have a similar function to stereotypes in decision-making by doctors. Our results may therefore suggest that decisions made by GPs for ethnic minority patients are based on over-generalizations rather than on the actual individual assessment of the patient. This phenomenon suggests that GPs are more likely to perceive ethnic minority patients (out-group members) in terms of their group stereotype and pay less attention to their individual characteristics. An alternative explanation could be that GPs may prescribe drugs in order to avoid becoming involved with lifestyle modification, which is a more demanding clinical activity requiring more interpersonal communication. For example, studies show that doctors with a longer mean consultation time explore the psychosocial dimension of illness in greater depth and prescribe fewer medications than doctors with shorter consultation times. The same authors also showed that, interestingly, the doctors who were devoting more time to patients were those who were experiencing higher stress levels associated with "running behind schedule" $[33,34]$. We speculate that, when facing ethnic minority patients, GPs may devote less time to them and prescribe them more medication as a coping strategy to avoid engaging in doctor-patient relations.

As regards the relational dimension of doctoring, ethnicity had no effect on the amount of time devoted by GPs to examining the patient's medical history. However, we found that GPs experiencing high volumes of activity devoted significantly less time to medical history examination for ethnic minority patients than did

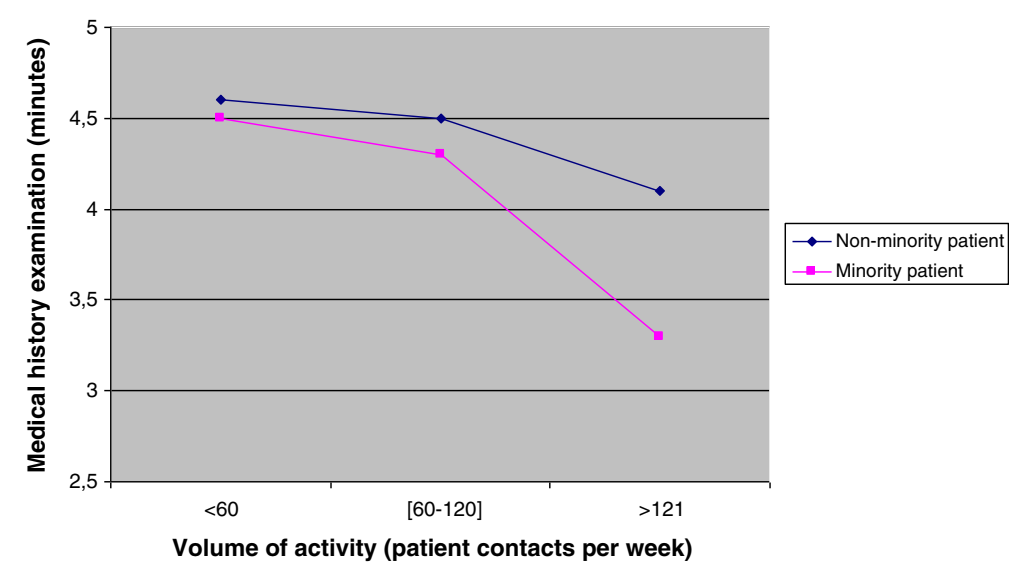

Figure 1 Interaction between patient's ethnicity and GPs' volume of activity in estimation of time devoted by GPs to medical history examination, Belgium, 2012. 
GPs with lower volumes of activity. This result is consistent with previous research that indicated that time pressure, cognitive load, necessity of prompt decisions, task complexity, busyness, distraction, fatigue, and anxiety increase the likelihood of stereotype usage [48-52]. Our findings therefore support the hypothesis that ethnic discrimination is likely to be context-dependent. Baron and Pfeffer showed that organizational practices mediate the cognitive biases and stereotypes of actors [53]. In addition, Reskin states that "the proximal cause of most discrimination is in the personal practices of work organization that polarize the biasing effects of automatic cognitive processes" ([54], p.320). The underlying idea is that discrimination is expressed only if certain organizational conditions are met [55]. We observed that the amount of time devoted by GPs to examining socio-relational history was significantly lower for ethnic minority patients. These results are consistent with Roter and Johnson's research, which revealed that doctors engaged in less psychosocial talk and more biomedical information-giving during interethnic consultations [22,23]. They are also consistent with Cooper, who found that race-discordant medical interactions were significantly shorter compared to race-concordant medical interactions [56]. When interacting with ethnic minority patients, GPs are thus focused on medical aspects of doctoring and put aside the socio-relational dimensions of doctoring. This is supported by previous findings. Doctors engaged in inter-ethnic consultations have been shown to be more reluctant to engage in partnership-building and emotional considerations [25]. The literature on doctorpatient communication supports the idea that white doctors are less comfortable when interacting with patients of other ethnic groups $[9,25]$.

There were at least three limitations to our study. Firstly, the participation rate was low (45\%). The representativeness of our sample is therefore limited. Our GP sample was over-representative of younger, female, and group-practice GPs when compared with the overall population of GPs in Belgium. This may mean that we surveyed a more "migrant friendly" group of GPs, since younger and female GPs have been shown to be more patient-centered and more concerned about vulnerable patients, compared to older, male doctors [57]. Secondly, case vignettes are not real clinical situations and it is difficult to determine whether the relational engagement with patient and medical decisions by GPs in case vignettes represent their true clinical activity. Thirdly, the relational dimension of doctoring involves more than the time devoted to the patient, which is only one of many aspects. Further studies, using more ethnographic methods, could consider other factors such as participatory style, warmth, empathy, and information giving/seeking, which are also essential aspects of the relational dimension of doctoring.

\section{Conclusion}

Good doctor-patient relations are essential for the effective management of chronic illness in general practice. In this study, we found that GPs self-report devoting less time to ethnic minority patients than to non-ethnic minority patients. This may suggest that ethnic discrimination in general practice occurs primarily through the relational dimension of doctoring. However, as our study design was experimental, our results require confirmation through the use of observational data and routine health care databases. We also observed that GPs in a constraining environment (high rate of patient contact) devoted less time to examining medical history for ethnic minority patients. This last finding suggests that ethnic discrimination is associated with resource allocation priorities and is therefore a context-dependent phenomenon. Further research should, firstly, aim to corroborate these ethnic differences in medical decisions with routine databases that allow GPs' prescriptions, patient clinical status, and patient ethnicity to be tracked. Secondly, further research should seek to understand why GPs engage less in the relational dimension of doctoring with ethnic minority patients. Third, could also attempt to identify key contextual variables that enhance the risk of ethnic discrimination. Further research is also necessary to replicate and confirm our findings. Research into the issue of ethnic discrimination in general practice potentially has important public health benefits. GPs are the gatekeepers to specialty care and play an important role in patient pathways. Discrimination may also magnify ethnic inequalities in health. Our study highlights the risk of inappropriate drug use in some ethnic-specific encounters.

\section{Additional file}

Additional file 1: Medical vignette used in the study.

Abbreviations

GP: General practitioner; GPs: General practitioners; ECG: Electrocardiogram.

Competing interests

All authors declare no competing interests.

\section{Authors' contribution}

BL conceived the study, performed the statistical analysis, and drafted the manuscript. $V L$ participated in the design of the study and helped to draft the manuscript. CR and PVM assisted with the interpretation of the data. All authors participated in the analysis and read and approved the final manuscript.

\section{Acknowledgements}

$B L$ would especially like to thank Professors $V L, C R$, and PVM for their valuable comments and support. BL would also like to thank Professor 
Dominique Pestiaux (Université Catholique Louvain, Faculty of Medicine) and Dr. Luc Lefebvre (Belgian Scientific Society of General Medicine) for their support and authorization.

Received: 18 March 2014 Accepted: 25 April 2014

Published: 9 May 2014

\section{References}

1. Nazroo JY: The structuring of ethnic inequalities in health: economic position, racial discrimination, and racism. Am J Public Health 2003, 93:277-284.

2. Mead H, Cartwright-Smith L, Jones K, Ramos C, Woods K, Siegel B: Racial and Ethnic Disparities in U.S. Health Care: A Chartbook. New York: The Commonwealth Fund; 2008.

3. National Center for Health Statistics: Statistics Health, United States, 2010: With Special Feature on Death and Dying. Hyattsville, MD: National Center for Health Statistics; 2011.

4. Orsi J, Margellos-Anast H, Whitman S: Black-white health disparities in the United States and Chicago: a 15-year progress analysis. Am J Public Health 2010, 100:349-356

5. Shavers VL, Klein WM, Fagan P: Research on race/ethnicity and health care discrimination: where we are and where we need to go. Am J Public Health 2012, 102:930-932.

6. Smedley B: Unequal Treatment: Confronting Racial and Ethnic Disparities in Health Care. Washington, D.C.: The National Academies Press; 2003.

7. Pager $\mathrm{D}$, Shepherd $\mathrm{H}$ : The sociology of discrimination: racial discrimination in employment, housing, credit, and consumer markets. Annu Rev Sociol 2008, 34:181-209.

8. van Ryn M: Research on the provider contribution to race/ ethnicity disparities in medical care. Med Care 2002, 40:1140-1151.

9. Burgess D, Fu S, van Ryn M: Why do providers contribute to disparities and what can be done about it? I Gen Intern Med 2004, 19:1154-1159.

10. Dovidio J, Kawakami K, Smoak N, Gaertner S: The roles of implicit and explicit processes in contemporary prejudice. In Attitudes: Insights From the New Implicit Measures. Edited by Petty R, Fazio R, Brinol P. New York: Psychology Press; 2009:165-192.

11. Burgess D, van Ryn M, Dovidio J, Saha S: Reducing racial bias among health care providers: lessons from social-cognitive psychology. J Gen Intern Med 2007, 22:882-887.

12. Dovidio J, Fiske S: Under the radar: how unexamined biases in decision-making processes in clinical interactions can contribute to health care disparities. Am J Public Health 2012, 102:945-952.

13. Dovidio J, Penner L, Albrecht T, Norton W, Gaertner S, Shelton J: Disparities and distrust: the implications of psychological processes for understanding racial disparities in health and health care. Soc Sci Med 2008, 67:478-486

14. Taiifel H: Experiments in intergroup discrimination. Sci Am 1970, 223:96-102.

15. van Ryn M, Fu S: Paved with good intentions: do public health and human service providers contribute to racial/ethnic disparities in health? Am J Public Health 2003, 93:248-255.

16. Schulman K, Berlin J, Harless W: The effect of race and sex on physicians' recommendations for cardiac catheterization. N Engl J Med 1999, 340:618-626.

17. Lewis G, Croft-Jeffreys C, David A: Are British psychiatrists racist? Br J Psychiatry 1990, 157:410-415.

18. van Ryn M, Burke J: The effect of patient race and socio-economic status on physicians' perceptions of patients. Soc Sci Med 2000, 50:813-828

19. Sabin J, Rivara F, Greenwald A: Physician implicit attitudes and stereotypes about race and quality of medical care. Med Care 2008, 40:678-685

20. Lee $C$, Ko C: Beyond outcomes the appropriateness of surgical care. JAMA 2009, 302:1580-1581.

21. Cooper $L$, Beach $M$, Johnson $R$, Inui $T$ : Delving below the surface. Understanding how race and ethnicity influence relationships in health care. J Gen Intern Med 2006, 21:21-27.

22. Roter D, Stewart M, Putman S, Lipkin M, Stiles W, Inui T: Communication patterns of primary care physicians. JAMA 1997, 277:350-356.

23. Johnson R, Roter D, Powe N, Cooper L: Patient race/ethnicity and quality of patient-physician communication during medical visits. Am J Publ Health 2004, 94:2084-2090
24. Kaplan S, Gandek B, Greenfield S, Rogers W, Ware J: Patient and visit characteristics related to physicians' participatory decision-making style. Results from the Medical Outcomes Study. Med Care 1995, 33:1176-1187.

25. Cooper-Patrick L, Gallo J, Gonzales J, Vu H, Powe N, Nelson C, Ford DE: Race, gender, and partnership in the patient-physician relationship. JAMA 1999, 282:583-589.

26. Uiters E, Devillé WLM, Foets $M$, Groenewegen PP: Use of health care services by ethnic minorities in The Netherlands: do patterns differ? Eur J Public Health 2006, 16:388-393.

27. STARFIELD B, SHI L, ACINKO J: Contribution of primary care to health systems and health. Milbank Q 2005, 83:457-502.

28. Nielsen $S$, Hempler $N$, Waldorff $F$, Kreiner $S$, Krasnik A: Is there equity in use of healthcare services among immigrants, their descendents, and ethnic Danes? Scand J Public Health 2012, 40:260-270.

29. Service Public Fédéral Economie P.M.E Classes Moyennes et Energie: Population par nationalité, sexe, groupe et classe d'âges au 1er janvier 20110. Bruxelles: Service Public Fédéral Economie; 2011.

30. Schoonvaere Q, Perrin N: Rapport statistique et démographique : Migrations et populations issues de limmigration en Belgique. Bruxelles: Centre pour l'égalité des chances et la lutte contre le racisme; 2010.

31. Beaulieu MD, Haggerty J, Tousignant P, Barnsley J, Hogg W, Geneau R, Hudon É, Duplain R, Denis JL, Bonin L, Del Grande C, Dragieva N: Characteristics of primary care practices associated with high quality of care. Can Med Assoc J 2013, 185:E590-E596.

32. Grieve S: Time availability in the consultation. Br J Gen Pract 1990, 40:167-168.

33. Howie JGR, Porter AMD, Forbes JF: Quality and the use of time in general practice: widening the discussion. Br Med J 1989, 298:1008-1010.

34. Howie JGR, Porter AMD, Heaney DJ, Hopton JL: Long to short consultation ratio: a proxy measure of quality of care for general practice. $\mathrm{Br} J \mathrm{Gen}$ Pract 1991, 41:48-54.

35. Martin CM, Banwell CL, Broom DH, Nisa M: Consultation length and chronic illness care in general practice: a qualitative study. Med J Aust 1999, 171:77-81.

36. Roland MO, Bartholomew J, Courtenay MJF, Morris RW, Morrell DC: The 'five minute' consultation: effect of time constraint on verbal communication. Br Med J 1986, 292:874-876.

37. Sturmberg JP, Cilliers P: Time and the consultation - an argument for a 'certain slowness'. J Eval Clin Pract 2009, 15:881-885.

38. Williams B, Poulter N, Brown M, Davis M, Mclnnes G, Potter J, Sever PS, Thom SM, BHS guidelines working party, for the British Hypertension Society: British Hypertension Society guidelines for hypertension management 2004 (BHS-IV): summary. BMJ 2004, 328:634-640.

39. Ruilope L: Current challenges in the clinical management of hypertension. Nat Rev Cardiol 2011, 9:267-275.

40. Hall-Lipsey E, Chisholm-Burns M: Pharmacotherapeutic disparities: racial, ethnic, and sex variations in medication treatment. Am J Health-Syst Pharm 2010, 67:462-468.

41. Winkleby M, Kraemer $\mathrm{H}$, Ahn D, Varaby A: Ethnic and socioeconomic differences in cardiovascular disease risk factors. JAMA 1998, 280:356-362.

42. Perrin N, Van Robaeyes B, Martiniello M, Vranken J: La pauvreté chez les personnes d'origine étrangère chiffrée. Brussels: Fondation Roi Baudouin; 2007. Rapport partiel de "Pauvreté chez les personnes d'origine étrangère".

43. Van Oyen H, Deboosere P, Lorant V, Charafeddine R: Les inégalités sociales de santé en Belqique. Gent: Academia Press; 2010.

44. Lorant V, Van Oyen H, Thomas I: Contextual factors and immigrants' health status: double jeopardy. Health Place 2008, 14:678-692.

45. Vandenheede $H$, Lammens L, Deboosere P, Gadeyne S, Despiegelaere M: Ethnic differences in diabetes-related mortality in the Brussels-Capital Region (2001-05): the role of socioeconomic position. Int J Public Health 2011, 56:533-539.

46. Vandenheede H, Deboosere P, Stirbu I, Agyemang C, Harding S, Juel K Rafnsson SB, Regidor E, Rey G, Rosato M, Mackenbach JP, Kunst AE: Migrant mortality from diabetes mellitus across Europe: the importance of socio-economic change. Eur J Epidemiol 2012, 27:109-117.

47. Balsa A, McGuire T: Prejudice, clinical uncertainty and stereotyping as sources of health disparities. J Health Econ 2003, 22:89-116.

48. Dijker A, Koomen W: Stereotyping and attitudinal effects under time pressure. Eur J Soc Psychol 1996, 26:61-74. 
49. Pratto F, Bargh J: Stereotyping based on apparently individuating information: trait and global components of sex stereotypes under attention overload. J Exp Soc Psychol 1991, 27:2647.

50. Gordon R, Anderson K: Perceptions of race stereotypic and race nonstereotypic crimes: the impact of response time instructions on attributions and judgements. Basic Appl Soc Psychol 1995, 16:455-470.

51. Bodehausen G, Lichtenstein M: Social stereotypes and information-processing strategies: the impact of task complexity. J Pers Soc Psychol 1987, 52:871-880.

52. Fiske S, Gilbert D, Lindzey G: The Handbook of Social Psychology. Boston, Mass: Wiley; 2010.

53. Baron J, Pfeffer J: The social psychology of organizations and inequality. Soc Psychol 1994, 57:190-209.

54. Reskin B: The proximate causes of employment discrimination. Contemp Sociol 2000, 29:319-328.

55. Petersen T, Sapaorta I: The opportunity structure for discrimination. Am J Sociol 2004, 109:852-901.

56. Cooper L, Roter D, Johnson R, Ford D, Steinwachs D, Powe N: Patient-centered communication, ratings of care, and concordance of patient and physician race. Ann Intern Med 2003, 139:907-915.

57. Law S, Britten N: Factors that influence the patient centredness of a consultation. Br J Gen Pract 1995, 45:520-524.

doi:10.1186/1471-2296-15-89

Cite this article as: Lepièce et al:: General practice and ethnicity: an experimental study of doctoring. BMC Family Practice 2014 15:89.

\section{Submit your next manuscript to BioMed Central and take full advantage of:}

- Convenient online submission

- Thorough peer review

- No space constraints or color figure charges

- Immediate publication on acceptance

- Inclusion in PubMed, CAS, Scopus and Google Scholar

- Research which is freely available for redistribution 